\title{
Functional assembly of tropical montane tree islands in the Atlantic forest is shaped by stress-tolerance, bamboo-invasion and facilitation
}

\author{
Tina Christmann ${ }^{1}$, Bruno H.P. Rosado ${ }^{2}$, Guillaume Delhaye ${ }^{1}$, ILAINE MATOS ${ }^{3}$, Helena \\ Roland $^{2}$, Yan Moraes ${ }^{2}$, Julia Drummond ${ }^{2}$, and Imma Oliveras ${ }^{1}$ \\ ${ }^{1}$ University of Oxford \\ ${ }^{2}$ Universidade do Estado do Rio de Janeiro \\ ${ }^{3}$ University of California Berkeley
}

April 18, 2021

\begin{abstract}
Aims: Amidst the Campos the Altitude (Highland Grasslands) in the Brazilian Atlantic Forest, woody communities grow either clustered in tree islands or interspersed within the herbaceous matrix. The functional ecology, diversity and biotic processes shaping these communities are largely unstudied. We characterised the functional assembly and diversity of these tropical montane woody communities and investigated how those communities fit within the Grime's CSR (C - competitor, S - stress-tolerant, $\mathrm{R}$ - ruderal) scheme, what trade-offs they exhibit and how traits and functional diversity vary in response to bamboo invasion. Methods: We sampled five leaf traits and wood density along transects covering the woody communities both inside tree islands and outside (i.e. woody plants in the grasslands community) to characterise the functional ecology of the community. We used Kruskal-Wallis test, t-test and variation partitioning to determine effects of inside vs outside the tree island and bamboo invasion on traits, woody species diversity and functional diversity. Results: We found a general $\mathrm{SC} / \mathrm{S}$ strategy with drought-related functional trade-offs. Woody plants in tree islands had more acquisitive traits, whereas woody plants within the grasslands had more conservative traits. Trait variation was mostly taxonomically driven, and species composition varied between inside and outside tree islands. Leaf thickness, wood density and foliar water uptake were unrelated to CSR-strategies, suggesting independent trait dimensions and multiple drought-coping strategies within the predominant Sstrategy. Bamboo-invaded islands showed lower Simpson diversity, lower functional dispersion, lower foliar water uptake and greater leaf thickness than non-invaded tree islands. Conclusions: The observed functional assembly in response to bamboo and facilitation have implications for future forest expansion and response of the communities to climate change. Further studies on eco-physiological and establishment traits and the mechanisms behind biotic interactions are needed to better understand the response of these communities to future environmental changes.
\end{abstract}

\section{Hosted file}

Functional_assembly_JoVS_Short_Christmann_etal.pdf available at https://authorea.com/users/ 408462/articles/518461-functional-assembly-of-tropical-montane-tree-islands-in-theatlantic-forest-is-shaped-by-stress-tolerance-bamboo-invasion-and-facilitation 